\section{FAITS DIVERS}

Taillande: Les tentatives de réunions se poursuivent

Les agents de l'ambassade du Canada à Bangkok en Thaillande signalent qu'ils ont de la difficulté à obtenir la permission d'interviewer des réfugiés dans tous les camps kampuchéens de ce pays. Ils notent cependant certaines améliorations depuis décembre, alors qu'on craignait un moratoire absolu sur l'étude des cas. Malgré certaines restrictions et les difficultés causées par les nombreuses allées et venues entre les camps, les agents de l'ambassade espèrent pouvoir régler tous les cas de réunion des familles.

\section{Entente de parrainage}

Le Canadian Polish Congress et le ministre de l'Emploi et de l'Immigration, M. Lloyd Axworthy, viennent de signer une entente concernant le parrainage de réfugiés. Grâce à cette entente, il sera maintenant plus facile pour les filiales ou les organisations membres du Congrès au Canada de parrainer des réfugiés au sens de la Convention des Nations Unies et les personnes qui se sont exilées des pays de l'Europe de l'Est, puisque le temps nécessaire à l'étude des demandes à été réduit et les formalités simplifiées au niveau local. Selon le plan établi pour 1981, 4000 réfugiés de l'Europe de l'Est viendront s'établir au Canada. en 1980, il y en a eu 3700 .

\section{Longue-Pointe ferme ses portes}

En août 1979, des centres d'accueil ont été aménagés à Longue-Pointe à Montréal et à Griesbach à Edmonton à l'intention des réfugiés indochinois.

Avec la diminution du nombre de réfugiés indochinois, le besoin d'offrir des services complets dans les centres d'accueil s'est amoindri. Ainsi, en août 1980, les pratiques au centre de Griesbach ont été progressivement éliminées et, comme le dernier des neuf vols nolisés prévus pour le programme de 1981 est arrivé le 25 mars 1981, le centre de Longue-Pointe a aussi fermé ses portes à la fin de mars. Depuis le début d'avril, tous les Indochinois arrivent au Canada par petits groupes d'une cinquantaine de personnes à bord de vols commerciaux réguliers à destination de l'aéroport international de Vancouver ou de Mirabel, près de Montréal.

Pour le reste de 1981, les services d'accueil seront offerts à ces points d'entrée. La plupart des réfugiés n'y passeront qu'une nuit dans des chambres d'hôtel retenues à cet effet par le gouvernement. Les formalités de l'agriculture et de la douane seront effectuées à ces endroits, les réfugiés y subiront un dernier examen médical, recevront des vêtements et rempliront leur demande de numéro d'assurance sociale. Tous les réfugiés seront munis de tous les documents voulus et connaitront leur destination finale. Autant que possible, on les aidera à s'y rendre le lendemain de leur arrivée au point d'entrée.

\section{LES MÉDIAS À L'AFFÛT}

\author{
LES RÉFUGIÉS DE LA MER: “CAUCHEMAR” OU \\ "ADAPTATION" \\ par Gerald Utting, \\ Toronto Star
}

Le rôle que les médias ont joué pour sensibiliser le public canadien au sort des réfugiés de la mer a fait ressortir de façon frappante l'influence que les médias peuvent exercer sur la réaction du public. REFUGE a donc demandé à des journalistes qui ont fait des reportages sur les réfugiés indochinois comment ils percevaient leur rôle dans ce cas particulier.

En mars dernier, un groupe d'étude a publié un rapport sur le sort des 12000 réfugiés de la mer installés à Toronto.

Selon l'article paru dans le Toronto Star, pour lequel je travaille incidemment, les réfugiés de la mer sont dans un état pitoyable, désespérément accablés par la vie trépidante de Toronto. Ils vivent entassés dans les logis, sont mal rémunérés et subissent un choc culturel, en plus d'avoir de la difficulté à surmonter les tensions provoquées par les "horreurs qu'ils ont connues sur la mer et dans les camps de réfugiés en Asie". Je n'ai pas lu le rapport, mais quel qu'en fut la teneur, la presse a titré: "Un beau rêve devenu cauchemar", et c'est ce que je trouve ridicule.

En effet, compte tenu des épreuves que les réfugiés de la mer et d'autres réfugiés ont subies à cause de la tyrannie, des meurtres et de la famine en Asie du SudEst, il est franchement risible d'affirmer que ces hommes, leurs courageuses épouses et leurs beaux enfants vivent un cauchemar à Toronto.

J'ai parlé à des centaines de réfugiés de la mer dans leurs camps fétides. J'ai vu sur une plage de la Malaysie des soldats armés de fusils automatiques, de matraques et de boucliers forcer des misérables en pyjamas noirs à former un groupe qui faisait vraiment pitié. En fait, j'ai aidé des gens à tirer des moribonds d'une frêle embarcation au large de la côte vietnamienne.

Je n'ai jamais entendu aucun de ces réfugiés se plaindre de ces conditions qui tenaient véritablement du cauchemar. Certes, ils voulaient fuir ces affreux camps de réfugiés dans les îles. Certes, ils étaient terrifiés d'être entourés d'hommes armés dans un pays étranger où ils espéraient trouver refuge. Certes, la soif et la faim sur leurs bateaux de fortune les avaient à ce point affaiblis qu'ils ne pouvaient rien faire d'autre que gémir. Mais ils étaient si heureux d'avoir fui leur pays où les conditions étaient telles qu'ils étaient prêts à risquer la mort pour y échapper.

Ce sont des gens courageux et débrouillards. Ce qu'ils vivent maintenant à Toronto et ailleurs au Canada, ce n'est pas un cauchemar, mais simplement les difficultés que suppose inévitablement l'adaptation à la vie dans un pays étranger. II est évident qu'ils ont besoin d'aide sur les plans financier, éducatif, médical et même psychologique. Rien d'étonnant pour des gens si éprouvés. Ils ont besoin surtout de compréhension et d'amitié, tout comme les autres Canadiens dans leur vie 